\title{
CONSIDERACIONES METODOLÓGICAS
}

\section{Locus de enunciación: criminología crítica o sociología jurídico-penal en oposición a la criminología positivista}

Esta segunda parte tiene por objeto presentar aquello que, de acuerdo con cierta opinión, constituye el ámbito de mayor impacto de la criminología crítica dentro de la realidad jurídico-penal. Por fuera de las discusiones políticas, la criminología crítica, entendida en un sentido amplio — es decir, como un conjunto de posturas críticas frente al sistema penal-, muestra su mayor riqueza en el campo epistemológico, dado que ha destruido la concepción positivista, normativista y técnico-jurídica del derecho penal. Por ello, el título del texto se refiere, en primera instancia, al carácter deconstructivo de esta visión. Deconstruye, por un lado, la definición legal del sistema penal y su pretendida objetividad y, por otro, la normalización de categorías jurídicas a través de discursos ontológicos y técnico-jurídicos.

Con ello se abre la posibilidad de reconstruir el sistema penal de una manera más compleja, de relacionarlo con la realidad social, con la lucha estratégica de poderes y dominios, al distinguir los discursos metajustificadores de las funciones reales del sistema, al poner en cuestión las promesas incumplidas del sistema y al mostrar lo que había pasado oculto, desapercibido para la criminología y el derecho penal. En vez de sistema penal, se utiliza la expresión cuestión criminal, no solo como homenaje a una tradición crítica que puede relacionarse con ella, 
sino porque nos permite superar la idea de sistema que, en sus distintas versiones (sistemas abiertos o sistemas cerrados), nos postra ante el superficial argumento de que la realidad social está definida por el orden y que existen límites, funciones y estructuras que pueden distinguirse a veces como figuras analíticas de comprensión de la realidad social, a veces como realidades naturales dentro de la sociedad. Se prefiere, entonces, en esta oportunidad a la cuestión criminal porque nos arroja al conflicto, la complejidad, la paradoja, la anomia, etc. Realidades que, en todo caso, se parecen más a América Latina.

Se necesita cierto grado de conciencia académica para darse cuenta de que a continuación se encontrarán apenas algunas líneas de los enfoques sociológicos y filosóficos que permiten la deconstrucción de la cuestión criminal y su reconfiguración desde una perspectiva alternativa. No son ideas culminadas, no es un tratado; son, por el contrario, los primeros acercamientos a la descripción de la caja de herramientas que durante años hemos utilizado para estudiar la realidad del sistema penal en nuestro país. En fin, se trata únicamente de un ejercicio de autoconciencia.

\section{La genealogía y la arqueología de Michel Foucault: el análisis de dispositivos en concreto}

La filosofía crítica de Michel Foucault ha tenido profundas repercusiones en el derecho penal y la criminología. Tal vez su libro más conocido sea Vigilar y castigar, que ya cumple cuarenta años de haber sido publicado. ${ }^{33}$ Por supuesto, Foucault estaba al tanto de las investigaciones que en distintos campos se hacían sobre el tema del castigo y la penalidad. Así ocurrió, por ejemplo, con el libro Pena y estructura social al que ya se ha hecho referencia anteriormente. Refiere el famoso filósofo francés respecto al gran libro de Rusche y Kirchheimer:

Se puede sacar cierto número de puntos de referencia esenciales. [...] En esta línea, Rusche y Kirchheimer han puesto en relación los diferentes regímenes punitivos con los sistemas de producción de los que toman sus efectos; así en una economía servil los mecanismos punitivos tendrían el cometido de aportar una mano de obra suplementaria, y de constituir una esclavitud "civil" al lado de la que mantienen las guerras o el comercio; con el feudalismo, y en una época en que la moneda y la producción 
están poco desarrolladas, se asistiría a un brusco aumento de los castigos corporales, por ser el cuerpo en la mayoría de los casos el único bien accesible, y el correccional - el Hospital general, el Spinhuis o el Rasphuis-, el trabajo obligado, la manufactura penal, aparecerían con el desarrollo de la economía mercantil. Pero al exigir el sistema industrial un mercado libre de la mano de obra, la parte del trabajo obligatorio hubo de disminuir en el siglo XIX en los mecanismos de castigo, sustituida por una detención con fines correctivos. Hay, sin duda, no pocas observaciones que hacer sobre esta correlación estricta. ${ }^{34}$

El origen de las prisiones expuesto allí le sirve para mostrar que el encierro de individuos para convertirlos en sujetos productivos, racionales, reproductivos o, en suma, normales es un dispositivo sumamente complejo que atraviesa a las sociedades occidentales y que, lejos de ser un acontecimiento aislado de interés únicamente para el erudito, en realidad constituye el centro de estructuración y constitución de la realidad moderna a la que el propio Foucault define como disciplinaria.

Se trata, por lo tanto, de una definición poco ortodoxa del mundo occidental que se autodefinía como racional y reflexivo. La Ilustración ponía a la razón como el cincel revolucionario que definía al hombre moderno. Esto permitía romper con la irracionalidad del pasado y construir el presente sin referencia alguna al pasado; de ahí el carácter revolucionario del pensamiento moderno. ${ }^{35} \mathrm{El} \mathrm{cos}-$ mopolitismo, el espíritu Absoluto, la reconciliación entre sujeto y objeto, etc., son definiciones racionales de la historia que se convierten en estandartes de la modernidad. La existencia misma de la realidad terminó por depender del sujeto que la conoce, como si este fuese una realidad dada, una estructura ontológica sobre la cual gravitaban la historia, los acontecimientos.

34 Michel Foucault, Vigilar y castigar: nacimiento de la prisión. México: Siglo XXI Editores, 1984, p. 31.

35 Así precisamente puede entenderse a la llustración según Foucault. En un texto que lleva como título ¿Qué es la Ilustración?, Foucault trata de analizar la actitud de Kant al hacerse esa misma pregunta y desglosar desde allí una definición de la llustración como pensamiento crítico. Expresa este autor: "Con frecuencia se intenta caracterizar a la modernidad por la conciencia de la discontinuidad del tiempo: ruptura de la tradición, sentimiento de la novedad y vértigo de lo que pasa". Más adelante señala: "La modernidad se distingue de la moda que se limita a seguir el curso del tiempo; es la actitud que permite captar lo que hay de heroico en el momento presente. La modernidad no es un hecho de sensibilidad para el presente fugitivo; es una voluntad de heroizar el presente". A esta forma de ser en el mundo es a lo que Foucault denomina como ontología del presente (Michel Foucault, ¿Qué es la llustración?, en Obras esenciales. Barcelona: Paidós, 2010, p. 981). 
Pero Foucault, al igual que los filósofos de la sospecha: Marx, Freud y Nietzsche ${ }^{36}$, desconfió de la razón. La urdimbre compleja a la que los humanos llamamos realidad, antes que depender de la razón, lo hace del deseo, del poder y de la economía. Aquello que creíamos dado, en realidad no era más que una construcción del hombre. El sujeto es un punto de llegada, y no un inicio. El sujeto es una invención, el sujeto racional también lo es. No hay, por consiguiente, una condición de naturaleza en la humanidad; más bien somos un producto histórico.

Así como se fabrican mercancías dentro de una fábrica, también se fabrican sujetos dentro espacios muy parecidos a la fábrica. El sujeto es un producto de las instituciones que marcan una espacialidad y una temporalidad reglada, normativizada a través de rígidas disciplinas. Se producen en serie sujetos de acuerdo con los moldes prefabricados a los que ha llegado la ciencia. Esos moldes demarcan, delimitan, normalizan. El punto de no retorno, es decir, el origen de un nuevo tipo de sociedad, ocurre cuando esas fábricas de sujetos se perfeccionan y enclavan a lo largo de todo el territorio moderno. Así, el humano empezó a vivir dentro de una sociedad en la que el espacio estaba dividido en instituciones: la familia, luego la escuela, luego el cuartel militar, luego la fábrica; en situaciones extremas, el hospital, el manicomio y la prisión. Todas ellas, instituciones en las que el humano transita a lo largo de su vida social.

Pero, ¿qué tienen en común estas instituciones? Primero: en todas ellas se producen sujetos de acuerdo con parámetros de normalidad. Hay sujetos normales y sujetos anormales. Así, en la familia se define la sexualidad y la religión; en la escuela, la sexualidad, una relación determinada con la verdad y una ética; en la fábrica, el trabajo y no el ocio; en el cuartel militar, la nación y la defensa de la sociedad; en el hospital, la salud, la higiene, la asepsia; en el manicomio, la cordura; y en la prisión, la reforma moral. En su lado opuesto, cada institución produce también la anormalidad, la define y la pone de telón de fondo. En la familia se produce la homosexualidad, el onanismo, la poligamia, la degeneración,

36 La expresión filósofos de la sospecha fue formulada por Paul Ricœur para referirse a los tres pensadores del siglo XIX que desenmascaran la llustración, al señalar que la racionalidad como hecho constitutivo de la ontología humana es una falsedad. Los tres expresan, cada uno desde perspectivas diferentes, la construcción social de la verdad y la existencia más bien de la irracionalidad o la inconsciencia dentro de la cultura moderna. Marx señala a la ideología como deformación de la realidad y, por lo tanto, como falsa conciencia; Nietzsche muestra al conocimiento como una invención del humano y plantea una genealogía de la verdad, según la cual la voluntad de poder se constituye en un hecho definitivo de su producción; Freud pone al descubierto que la mayoría de los actos humanos provienen de las pulsiones inconscientes. 
la orfandad; en la escuela, el hombre vulgar, inculto, irracional; en la fábrica, el ocioso, el pobre, el mendigo, el vagabundo, la prostituta, el alcohólico, el desocupado; en el cuartel militar ${ }^{37}$, el apátrida, el rebelde, el sedicioso, el extranjero, el invasor; en el hospital ${ }^{38}$, el apestado, el infectado, el sifilítico, el enfermo; en el manicomio, el loco, el psicópata, el sociópata, el esquizofrénico; y en la prisión ${ }^{39}$, el delincuente, el incorregible, el asesino, el ladrón. "Vigilar pasa a ser entonces una función definida, pero que debe formar parte integrante del proceso de producción; debe acompañarlo en toda su duración". ${ }^{40}$

Segundo: para producir sujetos se necesita un poder que someta a los individuos. Ese poder debe tener la capacidad de moldear a cada uno de los individuos que transitan dentro de una institución. Es un poder positivo porque produce y no elimina. No es un poder que causa la muerte, tortura y cercena miembros, no es un poder que se dirige al cuerpo de los individuos; es más bien un poder que crea formas de ser y de pensar, es un poder que produce subjetividades. Para producir son necesarios ciertos modos, técnicas o mecanismos. Esos modos de producción inician con la vigilancia. La cadena productiva inicia con la vigilancia, que es una forma de someter la conducta humana a una mirada que ausculta la totalidad de sus actos.

\footnotetext{
37 Sobre este tema puede observarse la entrevista que Jean Pierre-Barou realiza a Michel Foucault y que lleva como título El ojo de poder. Esta entrevista sirve de presentación de la traducción al español del famoso libro de Jeremy Benthan: El panóptico. Allí indica Foucault: "Parece que uno de los primeros modelos de esta visibilidad aislante había sido puesto en práctica en la Escuela militar de París en 1755 en lo referente a los dormitorios. Cada uno de los alumnos debía disponer de una celda con cristalera a través de la cual podía ser visto toda la noche sin tener ningún contacto con sus condiscípulos, ni siquiera con los criados" (en Jeremías Bentham, El panóptico. Madrid: Ediciones de La Piqueta, 1979, p. 10).
}

38 "El hospital como instrumento terapéutico es un concepto relativamente moderno que data de fines del siglo XVIII. Alrededor de 1760, surge la idea de que el hospital puede y debe ser un instrumento destinado a curar el enfermo. Esto se produce a través de una nueva práctica: la visita y al observación sistemática y comparada de los hospitales. [...] ¿Qué es lo que surge en esa época? Un arte de distribución espacial de los individuos. [...] La disciplina es, ante todo, un análisis del espacio; es la individualización por el espacio, la colocación de los cuerpos en un espacio individualizado que permita la clasificación y las combinaciones. [...] La vigilancia es una técnica de poder que encierra una vigilancia constante y perpetua de los individuos. No basta con observarlos de vez en cuando o con ver si lo que hacen se ajusta a las reglas. Es preciso vigilarlos sin cesar para que se realice la actividad y someterlos a una pirámide permanente de vigilancia" (Michel Foucault, La incorporación del hospital en la tecnología moderna, en Obras esenciales. Barcelona: Paidós, 2010, pp. 771-773).

39 "Lo que ha remplazado al suplicio no es un encierro masivo, es un dispositivo disciplinario cuidadosamente articulado" (Michel Foucault, Vigilar y castigar: nacimiento de la prisión, op. cit., p. 269).

40 lbíd., p. 179. 
El ojo del poder debe llegar a todos los espacios en los que el individuo actúa: la alimentación, la higiene, la sexualidad, la reproducción, el trabajo, el estudio, la religión, la interacción social, etc. Pero tal grado de observación se dificulta en el laberinto, en las mazmorras, en las cavernas de tortura de la inquisición. Se hacen necesarias arquitecturas iluminadas, con pasillos amplios, transparentes. Se construyen entonces panópticos, es decir, edificios en los que puede observarse la totalidad de los actos de los seres humanos:

El panóptico era un sitio en forma de anillo en medio del cual había un patio con una torre en el centro. El anillo estaba dividido en pequeñas celdas que daban al interior y al exterior y en cada una de esas pequeñas celdas había, según los objetivos de la institución, un niño aprendiendo a escribir, un obrero trabajando, un prisionero expiando sus culpas, un loco actualizando su locura, etc.

En la torre central había un vigilante y como cada celda daba al mismo tiempo al exterior y al interior, la mirada del vigilante podía atravesar toda la celda, en ella no había ningún punto de sombra y por consiguiente, todo lo que el individuo hacía estaba expuesto a la mirada de un vigilante que observaba, [...] el panoptismo que, en mi opinión, es uno de los rasgos característicos de nuestra sociedad: una forma que se ejerce sobre los individuos a la manera de vigilancia individual y continua, como control de castigo y recompensa y como corrección, es decir, como método de formación y transformación de los individuos en función de ciertas normas. Estos tres aspectos del panoptismo — vigilancia, control y corrección - constituyen una dimensión fundamental y característica de las relaciones de poder que existen en nuestra sociedad. ${ }^{41}$

El modelo propuesto por Jeremías Bentham fue tan poderoso que se convirtió en la tecnología de control de los individuos en la modernidad capitalista e imprimió al poder una finalidad que terminaría creando un nuevo tipo de sociedad a la que Foucault denominó sociedades de la disciplina: "Se trata de una forma de poder, un tipo de sociedad que yo llamo sociedad disciplinaria". ${ }^{42}$

Así, la mirada no solo ve, sino que además controla. Luego, dentro de tal cadena de producción se registran los comportamientos y se corrigen: "La disciplina fabrica individuos; es la técnica específica de un poder que toma a los 
individuos a la vez como objetos y como instrumentos de su ejercicio". ${ }^{43}$ Para ello hay un control del tiempo y se crean reglamentos en los que hay cronogramas, temporalidades regladas, itinerarios. El reglamento administra el tiempo de los individuos. También los corrige a través de sistemas de premios y castigos. El individuo termina por acostumbrarse a estos regímenes temporales, termina por ser aconductuado, normalizado, reformado, disciplinado.

La disciplina esculpe tipos de sujetos, se convierte en un ejercicio minucioso que culmina con la reforma de la conducta del individuo. Es un poder ortopédico porque funciona como un corsé, un molde al que el individuo termina acostumbrándose. La disciplina es una ortopedia: viene de ortos, que significa 'recto', 'derecho', 'libre de deformidad', y de peis, que puede ser traducido como 'niño'. Así, la ortopedia es el poder de corregir deformidades en los niños. En ese sentido puede entenderse el poder disciplinario, es decir, como un conjunto de técnicas de corrección de las anormalidades, de las deformidades: "La disciplina es una anatomía política del detalle". ${ }^{44}$

Tercero: este poder termina por extenderse a lo largo de toda la sociedad. No es el Estado quien lo ejerce de arriba hacia abajo; más bien se ejerce todo el tiempo y sobre todos. Las instituciones terminan por estar presentes en todos lados, y los seres humanos pertenecen al ámbito social porque transitan todo el tiempo dentro de las instituciones. El poder se entiende mejor como una relación. Todos somos vigilados. Como diría Bentham, incluso quienes vigilan luego son vigilados. El poder, entonces, no es algo que se tiene, es más bien una relación estratégica:

Entre cada punto del cuerpo social, entre un hombre y una mujer, en una familia, entre un maestro y su alumno, entre el que sabe y el que no sabe, pasan relaciones de poder que no son la proyección pura y simple del gran poder del soberano sobre los individuos; son más bien el suelo movedizo y concreto sobre el que ese poder se incardina, las condiciones de posibilidad de su funcionamiento. ${ }^{45}$

Unos vigilan y otros se resisten a esa vigilancia. Se trata más bien de relaciones de poder. Aparece entonces una trama específica de relaciones de poder. Hay

43 lbíd., p. 199.

44 lbíd., p. 143.

45 Michel Foucault, Microfísica del poder. Madrid: Ediciones de La Piqueta, 1979, p. 157. 
sujeciones específicas y resistencias específicas, localizadas. Donde hay poder puede haber libertad. Y es precisamente a esta forma de poder a la que el pensador francés denomina microfisica del poder. Esta es indudablemente una forma de romper con el modo en que se entendía el poder en momentos en los que se afirmaba que él estaba en manos de las clases más poderosas y que el Estado y el derecho eran burgueses, es decir, mecanismos a través de los cuales se aseguraban los intereses de dichas clases. Desde esta fórmula tradicional del poder, este es negativo, niega y limita:

Se trataría de un poder cuyo modelo sería esencialmente jurídico, centrado en el solo enunciado de la ley y el solo funcionamiento de lo prohibido. Todos los modos de dominación, de sumisión, de sujeción se reducirán en suma al efecto de la obediencia. ${ }^{46}$

Desde la perspectiva de las relaciones de poder, este "no es una institución, y no es una estructura, no es cierta potencia de la que algunos estarían dotados: es el nombre que se presta a una situación estratégica compleja en una sociedad dada". ${ }^{47}$ Así, el poder se produce en todo momento y en todos los puntos. En particular se ejerce de una forma organizada y especialmente efectiva dentro de las instituciones. El poder se asegura allí, gracias a la existencia de un complejo cúmulo de mecanismos de vigilancia, control y disciplina:

[...] ¿Qué es el poder? O más bien — porque la pregunta “¿qué es el poder?” sería justamente una cuestión teórica que coronaría el conjunto, cosa que yo no quiero-, la apuesta consiste en determinar cuáles son, en sus mecanismos, sus efectos, sus relaciones, esos diferentes dispositivos de poder que se ejercen, en niveles diferentes de la sociedad, en ámbitos y con extensiones tan variadas. ${ }^{48}$

Si bien el poder puede observarse en todas partes, es precisamente dentro de las instituciones donde se ejerce de la forma más estratégica; se trata de aquellos espacios en los que el sujeto es especialmente normalizado:

Por una vez el poder no se oculta, no se enmascara, se muestra como tiranía llevada hasta los más ínfimos detalles, poder cínico al mismo tiempo puro, enteramente justificado ya que puede formularse enteramente en el interior de una moral que

46 Michel Foucault, Historia de la sexualidad 1. La voluntad de saber. México: Siglo XXI Editores, 1991, p. 104. 47 Michel Foucault, Defender la sociedad. México: Fondo de Cultura Económica, 2005, p. 113.

48 Michel Foucault, Historia de la sexualidad 1..., op. cit., p. 26. 
enmascara su ejercicio: su tiranía salvaje aparece entonces como dominación serena del Bien sobre el Mal, del orden sobre el desorden. ${ }^{49}$

Para Foucault son tres los espacios en los que se construyen los sujetos a raíz de las relaciones de poder: las instituciones, los saberes (dentro de los cuales las ciencias humanas tienen por objetivo la construcción del sujeto, en tanto que allí se convierte en objeto) y el sujeto (que puede construirse a sí mismo a partir de una ética práctica que denomina el cuidado de sí y que rescata dentro del pensamiento grecolatino en filósofos como Sócrates, Seneca y Marco Aurelio).

Es muy interesante la propuesta de Foucault en relación con el cuidado de sí, por cuanto constituye uno los únicos apartados de su pensamiento con carácter propositivo. Es precisamente aquí donde el filósofo intenta encontrar una salida a la asfixiante dinámica de la modernidad en la que todos somos objeto del poder $\mathrm{y}$, por lo tanto, producto de sus técnicas de producción de subjetividades. De acuerdo con el curso que ha sido publicado en español con el título La hermenéutica del sujeto $^{50}$, los seres humanos podemos ejercer una ética práctica respecto a la cual somos capaces de autoconstruirnos como si fuésemos obras de arte.

Para ello, Foucault rescata la ética socrática que parte de la expresión que da la bienvenida a los visitantes del oráculo de Delfos, la cual reza: Conócete a ti mismo. Según esta consigna, el primer paso para la virtud es el conocimiento de sí mismo. Quien se conoce a sí mismo luego puede tener una relación adecuada consigo mismo. Esa relación permite al individuo autoconstruirse como si se tratase de una escultura. Ello implica primero una estética (esculpirnos a nosotros mismos), luego una ética (ejercer la libertad al autoconstruirnos) y finalmente una política (dado que quien se conoce a sí mismo y se construye a sí mismo puede sostener relaciones adecuadas con los otros y, por lo tanto, puede gobernarlos). ${ }^{51}$

Así, bien puede decirse que, con sus investigaciones, Foucault buscó hacer una crítica al sujeto moderno para mostrar que la subjetividad que está en juego es la de cada

49 Michel Foucault, Microfísica del poder, p. 81.

50 Foucault desarrolla un curso denominado La hermenéutica del sujeto en el Collège de France, el cual inició el 6 de enero de 1982. En 1976, Foucault había presentado el primer tomo de la Historia de la sexualidad (La voluntad de saber), y mientras dictaba este curso se encontraba redactando los dos últimos tomos, publicados en 1984 como El uso de los placeres y La inquietud de sí. Este curso desarrolla con mayor detalle aquello que aparecería más tarde en el tercer tomo de la Historia de la sexualidad.

51 Michel Foucault, La ética del cuidado de sí como práctica de libertad, en Obras esenciales. Barcelona: Paidós, pp. 1027-1046. 
uno de nosotros y que tal subjetividad se encuentra "sujeta" a saberes y poderes que la expresan, constituyen e incluso normalizan. Y que Foucault realizó todo ello sólo por querer dar alas a la existencia individual y a aspirar a que a los seres humanos nos sea lícito hacer de nuestra vida una obra de arte. ${ }^{52}$

Además de la constitución de las subjetividades dentro de las instituciones y como procesos de autocuidado, existe una producción discursiva acerca de lo humano en el campo de las ciencias humanas, las cuales generan discursos de verdad sobre el sujeto, es decir, subjetividades. Las ciencias humanas, "este cuerpo de conocimientos (pero quizá esta palabra misma sea demasiado fuerte: digamos, para ser aún más neutros, a este conjunto de discursos) que toma por objeto al hombre en lo que tiene de empírico" ${ }^{53}$ y que son propias de la modernidad, nacen con el antropocentrismo, con el Renacimiento y con el humanismo ilustrado:

El campo epistemológico que recorren las ciencias humanas no ha sido prescrito de antemano: ninguna filosofía, ninguna opción política o moral, ninguna ciencia empírica sea la que fuere, ninguna observación del cuerpo humano, ningún análisis de la sensación, de la imaginación o de las pasiones ha encontrado jamás, en los siglos XVII y XVIII, algo así como el hombre, pues el hombre no existía (como tampoco la vid, el lenguaje y el trabajo); y las ciencias humanas no aparecieron hasta que, bajo el efecto de algún racionalismo presionante, de algún problema científico no resuelto, de algún interés práctico, se decidió hacer pasar al hombre (a querer o no y con un éxito mayor o menor) al lado de los objetos científicos, en cuyo número no se ha probado aún de manera absoluta que pueda incluírsele; aparecieron el día en que el hombre se constituyó en la cultura occidental a la vez como aquello que hay que pensar y aquello que hay que saber. ${ }^{54}$

En la constitución de la realidad moderna participan de forma compleja múltiples variables; sin embargo, en la filosofía de Foucault pueden distinguirse de forma constante tres. Por un lado, la verdad, que es definida como discursos de verdad, dado su carácter relativo y estratégico. Los discursos de verdad son el punto de llegada de las prácticas sociales, económicas, políticas y culturales. Las prácticas terminan por construir una serie de relaciones estratégicas dentro de las cuales terminan surgiendo discursos de verdad, normatividades y saberes.

52 Óscar Martiarena, Estudios sobre Foucault. México: Universidad Veracruzana, 2005, p. 106.

53 Michel Foucault, Las palabras y las cosas. Una arqueología de las ciencias humanas. México: Siglo XXI Editores, 2005, p. 334.

54 lbíd., pp. 334-335. 
Así, por ejemplo, de las prácticas económicas de la sociedad industrial surgen verdades que son propias para ese conjunto de relaciones a las que llamamos $c a-$ pitalismo. Max Weber ${ }^{55}$ demuestra que el capitalismo surgió en gran medida bajo el influjo de las prácticas culturales de la religión protestante sobre la pobreza, el trabajo, el ascetismo y el ahorro. Esas prácticas del protestantismo terminan constituyéndose en discursos de verdad que definen al hombre y que se constituyen en escenarios normativos que luego se impondrán a todos los individuos dentro de una realidad determinada, para forjarlos, corregirlos o simplemente darles un sentido. Los discursos de verdad son, al mismo tiempo, palabra y acontecimiento, palabra y cosa:

Discurso como estrategia a la manera de lo que hacen los anglosajones, en particular Wittgenstein, Austin, Strawson, Searle. Lo que me parece limitado en el análisis de la estrategia de un discurso que se realiza alrededor de una taza de té, en un salón de Oxford, que solo hablan de juegos estratégicos que son interesantes pero que me parecen limitados. El problema sería saber si no se puede estudiar la estrategia de un discurso en un contexto más real o en el interior de prácticas que son diferentes de las conversaciones de salón. Por ejemplo, en las historia de las prácticas judiciales me parece que puede aplicar una hipótesis, proyectar un análisis estratégico del discurso en el interior de los procesos históricos reales e importantes. ${ }^{56}$

En ese sentido, Foucault afirma en el texto La verdad y las formas jurídicas que uno de los principales objetivos de las investigaciones que presentará a lo largo de sus cinco conferencias es mostrar cómo las prácticas sociales pueden "llegar a engendrar dominios de saber que no solo hacen que aparezcan nuevos objetos, conceptos y técnicas, sino que hace nacer además formas nuevas de sujetos y por lo tanto sujetos de conocimiento". ${ }^{57}$ Ello implica, por un lado, que la noción de discurso de verdad a la que se refiere caracterice a los discursos no solo como hechos lingüísticos, sino además como un terreno estratégico y táctico de lucha, y allí la verdad se concibe como aquella que se impone a otras verdades. Por esta razón, Foucault rescata a la escuela de los sofistas de la Antigüedad griega.

Por otro, el sujeto se comprende como el discurso de verdad más importante de la modernidad. Y, finalmente, el poder, que anuda a los otros dos y los define. 
Las relaciones de verdad producen regímenes de verdad dentro de los cuales figura el sujeto: "Después de todo somos juzgados, condenados, clasificados, obligados a competir, destinados a vivir de un cierto modo o a morir en función de unos discursos verdaderos que conllevan efectos específicos de poder". ${ }^{58}$

Se trata de demostrar la relación existente entre los discursos de verdad y las relaciones de poder, lo cual nos permite expresar que el sujeto anormal y el criminal son construcciones propias de las sociedades disciplinares. En el curso impartido por Foucault en 1975, denominado Los anormales ${ }^{59}$, el autor señala que aquello que nosotros entendemos por delincuente, por criminal, se originó dentro de las prácticas judiciales y psiquiátricas de los siglos XVII y XVIII. Las prácticas judiciales sobre la imputabilidad y la inimputabilidad dan cabida al discurso de los psiquiatras, que construyeron un discurso médico que pretendía distinguir al loco del delincuente. Terminan por crear una definición a medio camino entre las dos categorías, por cuanto se reconoce la capacidad del delincuente para entender la ilicitud de su acto, pero al mismo tiempo, y tratándose de delitos de sangre escandalosos, se reconoce cierta monstruosidad o anormalidad en el delincuente. La dirección del trabajo de Foucault es definida por él mismo de la siguiente manera:

¿A través de qué juegos de verdad se da el hombre a pensar su propio ser cuando se percibe como loco, cuando se contempla como enfermo, cuando se reflexiona como ser vivo, como ser hablante y como ser de trabajo, cuando se juzga y se castiga en calidad de criminal? ¿A través de qué juegos de verdad el ser humano se ha reconocido como hombre de deseo ? $^{60}$

Ello nos permitirá deconstruir el aparato discursivo sobre el cual se ha construido la realidad penal y, por lo tanto, mostrar que existen otros discursos que plantean categorías y definiciones distintas, así como políticas en materia del delito completamente alternativas a las existentes. Precisamente a ello se refiere el título de la presente investigación. Por ello, se intentarán aclarar algunos aspectos referidos fundamentalmente al carácter genealógico y luego arqueológico de esta propuesta. Partiremos de la pregunta que el propio Foucault ha desarrollado a lo

58 Michel Foucault, Microfísica del poder, p. 140.

59 Michel Foucault, Los anormales. México: Fondo de Cultura Económica, 2000.

60 Michel Foucault, Historia de la sexualidad 2. El uso de los placeres. México: Siglo XXI Editores, 1993, p. 10. 
largo de sus investigaciones para dar respuesta a problemas que atañen al campo de la cuestión criminal: ¿cómo se formaron dominios de saber a partir de las prácticas sociales?

Por ello, en La verdad y las formas jurídicas se hace referencia al proceso penal, que es un conjunto de prácticas jurídicas a través de las cuales se pretende reconstruir la verdad sobre el crimen en disputa procesal. Estos mecanismos han variado a lo largo de la historia; para cada época hay un conjunto de reglas y relaciones que definen las prácticas jurídicas, y a su vez, cada conjunto de prácticas jurídicas construye la verdad de forma distinta. En la Antigüedad griega, en la época medieval, durante el feudalismo, luego en la monarquía absoluta y finalmente en la modernidad, los procedimientos jurídicos son diferentes y, por lo tanto, la verdad también. En las sociedades de la disciplina, las prácticas jurídicas a través de las cuales se construye la verdad sobre la criminalidad y sobre el criminal dependen de una técnica que Foucault denominó el examen:

Tenemos así, a diferencia del gran saber de indagación que se organizó en la Edad Media a partir de la confiscación estatal de la justicia y que consistía en obtener los instrumentos de reactualización de hechos a través del testimonio, un nuevo saber totalmente diferente, un saber de vigilancia, de examen, organizado alrededor de la norma por el control de los individuos durante toda su existencia. Esta es la base del poder, la forma del saber-poder que dará lugar ya no a grandes ciencias de observación como en el caso de la indagación, sino a lo que hoy conocemos como ciencias humanas: Psiquiatría, Psicología, Sociología, etcétera. ${ }^{61}$

Según lo expresado en La verdad y las formas jurídicas, en el siglo XIX los problemas jurídicos se resolvieron a partir de la técnica del examen, que sustituye a la técnica judicial de indagación propia del feudalismo. El examen como técnica judicial queda retratado en el expediente o dossier que Foucault y otros investigadores del Collége de France pusieron al descubierto, en el cual se describe todo el debate judicial acerca del asesinato protagonizado por Pierre Rivière, "de veinte años, considerado por los vecinos como idiota", que "mata cruelmente a la madre, a la hermana y al hermano, el 3 de junio de 1815, en un pueblo del Norte de Francia". ${ }^{62}$ En dicho dossier se transcriben los informes de tres médicos

61 Michel Foucault, La verdad y las formas jurídicas, op. cit, p. 91.

62 Michel Foucault, Yo, Pierre Rivière, habiendo degollado a mi madre, mi hermana y mi hermano... Un caso de parricidio del siglo XIX presentado por Michel Foucault. Barcelona: Tusquets, 1976, p. 3. 
psiquiatras (uno rural, otro director de un manicomio y, por último, psiquiatras famosos en Francia). Asimismo, los testimonios de vecinos y la versión del propio Rivière sobre el parricidio. Lo importante del caso Rivière es esto:

A partir del parricidio hay que remontar al móvil. Todo delito debe servir a la sociedad, debe ser instrumentalizado con miras a un castigo ejemplar, con el fin de evidenciar el mecanismo criminal desde el momento de su maduración hasta el de su realización. Un delito sin móvil es inimaginable, en cuanto es gratuito e inútil. ${ }^{63}$

Los tres informes de los médicos psiquiatras están fundamentados en la técnica del examen, es decir, la descripción detallada del criminal, su niñez, los posibles traumas, las patologías que provienen de la niñez de criminal, sus rasgos físicos, su contexto social; en suma, todo aquello que constituye la existencia del criminal. El examen, por lo tanto, como técnica judicial a través de la cual se construye la verdad sobre el crimen, está fundado en el criminal: "En nuestro caso, no es preciso ir muy lejos. Dado que Pierre Rivière, según la opinión común, es un alienado mental, el móvil se identifica con su locura". ${ }^{64}$

El examen del conjunto de determinaciones que obligan a un criminal a cometer crímenes brutales es un procedimiento que tuvo su nacimiento en el seno de las sociedades de la disciplina descritas por Foucault. El examen, según Foucault, se constituyó a mediados del siglo XVIII en un conjunto de tácticas empleadas para llegar a la verdad; una verdad que versa ya no sobre la indagación de si alguien cometió o no un delito, sino que se organiza alrededor de la norma, establece qué es normal y qué no lo es, qué cosa es incorrecta y qué otra cosa es correcta, qué se debe o no hacer.

El examen se apoya en la figura del panóptico, debido a que a través de este se ejerce una vigilancia permanente sobre los individuos para verificar si se comportan o no de acuerdo con la norma:

Esta es la base del poder, la forma del saber-poder que dará lugar ya no a grandes ciencias de la observación como en el caso de la indagación, sino a lo que hoy conocemos como ciencias humanas: psiquiatría, psicología, sociología, etcétera. ${ }^{65}$

63 Véanse los comentarios a la manera de prólogo para la edición en español de Angelo Morino, en Michel Foucault, Yo, Pierre Rivière, habiendo degollado a mi madre, mi hermana y mi hermano... Un caso de parricidio del siglo XIX presentado por Michel Foucault, p. 3.

64 lbíd.

65 Michel Foucault, La verdad y las formas jurídicas, op. cit., p. 100. 
Y agregaríamos también a la criminología. Podría afirmarse, entonces, que el examen tiene dos facetas: una que permite, a través de la observación pormenorizada de los individuos, la construcción de parámetros de normalidad y de anormalidad; y otra en la que se somete al individuo infractor a los ya construidos parámetros de normalidad. Sobre este particular, Foucault afirma:

Los individuos sobre los que se ejerce el poder pueden ser el lugar de donde se extrae el saber que ellos mismos forman y que será retranscrito y acumulado según nuevas normas; o bien pueden ser objetos de un saber que permitirá a su vez nuevas formas de control. ${ }^{66}$

Ahora bien, el examen como práctica para obtener la información sobre el individuo criminal y para posteriormente normalizarlo adquiere dimensiones particulares a partir de la irrupción del crimen monstruoso en la justicia penal a finales del siglo XVIII y comienzos del XIX. La intervención de la medicina mental y de la criminología en la institución penal para explicar los crímenes monstruosos implicó la integración de la conducta general del criminal al acto particular por medio del cual se cometía un delito. A partir de ese momento, las causas o los motivos fueron necesarios para determinar el castigo de un crimen.

Con la irrupción de las teorías criminológicas del positivismo antropológico de la escuela italiana, que culminaron en las teorías de la defensa social en Alemania y Bélgica, los motivos del crimen monstruoso se plantearon en relación con los antecedentes y las características físicas, psicológicas y sociales del criminal, del individuo peligroso. Ello quiere decir, entonces, que existen prácticas sociales dentro de las cuales se contienen a su vez prácticas económicas, culturales y epistemológicas propias de la ciencia, tales como las prácticas relativas al poder, las prácticas jurídicas, como lo muestra Foucault en su texto La verdad y las formas jurídicas.

Se afirmó anteriormente que la visión de las prácticas sociales de Foucault es de corte materialista, en la medida en que entiende por estas a un conjunto de relaciones a partir de las cuales surgen verdades, concebidas estas como discursos de verdad. Existirá entonces un campo específico del conocimiento que se encargue de describir detalladamente estas prácticas sociales que están contenidas en el mundo fenomenológico, en el mundo de los fenómenos, en los acontecimientos; 
es decir, el acontecimiento es el fenómeno en el que las prácticas sociales están contenidas en el mundo social.

En consecuencia, es apenas lógico anotar que si la pretensión de un investigador es la de describir, relatar aquellas prácticas sociales o jurídicas - a partir de las cuales surge la verdad-, entonces será necesario construir un método a partir del cual puedan describirse con detalle dichas prácticas, para mostrar, como lo indica el propio Foucault, que las prácticas jurídicas cambian a lo largo de la historia y que, además, como consecuencia de estos cambios, surgen a su vez discursos de verdad, que, como es lógico, cambian a lo largo de la historia.

Es importante reiterar que en el ámbito metodológico existente en el momento en que Michel Foucault propone este cúmulo de investigaciones hay una especie de crisis en dos ámbitos disciplinares a los cuales hace referencia constantemente. El primer ámbito es el de la historia, según la cual se cuentan de manera sintética los fenómenos que constituyen una época, a través de una mirada antropocentrista que centra y organiza todos los acontecimientos de la historia en relación con la conciencia del hombre. Por otro lado, la historia ha sido contada a partir del esquema que domina, que es hegemónico dentro de la filosofía occidental, entendida esta como pensamiento metafísico. En otras palabras, la filosofía, en particular la filosofia de la historia, ha organizado la infinitud de acontecimientos que constituyen una época mediante la idea del progreso:

En lugar de aquella cronología continua de la razón, que se hacía remontar invariablemente al inaccesible origen, a su apertura fundadora, han aparecido unas escalas a veces breves, distintas las unas de las otras, rebeldes a una ley única, portadoras a menudo de un tipo de historia propio de cada una, e irreductibles al modelo general de una conciencia que adquiere, progresa y recuerda. ${ }^{67}$

Occidente ha mostrado en su historia desde la Antigüedad griega hasta la modernidad y, por qué no decirlo, hasta la posmodernidad, el progreso de la humanidad, de la civilización, de la sociedad a partir de la idea de razón universal expresada por Kant en su razonamiento ya famosa del cosmopolitismo y la paz perpetua, y más tarde expresadas en la filosofía de la historia de Hegel a través de la noción de reflexividad (o conciencia del espíritu) de la sociedad, del sujeto colectivo. Esta conciencia es cada vez más madura en relación con el proceso de 
acercamiento a la idea y realización del absoluto hasta un punto culmen evolutivo de la sociedad, es decir, de mayor madurez y de conciencia interna de la humanidad, al cual el propio Hegel denominó Espíritu Absoluto:

Y el gran problema que va a plantearse — que se plantea — en tales análisis históricos no es ya el de saber por qué vías han podido establecerse las continuidades, de qué manera un solo y mismo designio ha podido mantenerse y constituir, para tantos espíritus diferentes y sucesivos, un horizonte único, qué modo de acción y qué sostén implica el juego de las trasmisiones, de las reanudaciones, de los olvidos y de las repeticiones, cómo el origen puede extender su ámbito mucho más allá de sí mismo y hasta ese acabamiento que jamás se da; el problema no es ya de la tradición y del rastro, sino del recorte y del límite; no es ya el del fundamento que se perpetúa, sino el de las transformaciones que valen como fundación y renovación de las fundaciones. ${ }^{6}$

En consecuencia, la historia, la historia global, tal y como lo había anotado Walter Benjamin, la historia que cuentan los vencedores, no los vencidos, no puede ser el método a través del cual puedan describirse de forma detallada las prácticas sociales. Es precisamente allí donde surge, en el pensamiento crítico, la propuesta de un método genealógico, al retomar las enseñanzas del filósofo alemán Federico Nietzsche en textos como Gaya Ciencia, Ecce homo o La genealogía de la moral. Lo primero que podemos anotar es la idea de Nietzsche en su autobiografía, según la cual intenta romper con la historia, con la filosofía de su tiempo, al anotar que la genealogía y sus tratados son inquietantes por cuanto incomodan a la tradición. El filósofo expresa acerca de sus investigaciones sobre la moral:

Tanto mi curiosidad como mis sospechas tuvieron que detenerse tempranamente en la pregunta sobre qué origen tienen propiamente nuestro bien y nuestro mal, $[\ldots]$ ¿en qué condiciones se inventó el hombre esos juicios de valor que son las palabras bueno y malvado? ${ }^{69}$

La labor de la genealogía es deconstructiva, prepara el terreno, allana el camino. Tal vez pueda entenderse esta idea de inicio y de transvaloración a través de lo que se indica en el libro Así hablaba Zaratustra: "Espíritu se convierte en

68 Ibíd., p. 7.

69 Federico Nietzsche, La genealogía de la moral. Madrid: Alianza, 2005, p. 24. 
camello; el camello, en león, y finalmente el león, en niño". ${ }^{70}$ El camello es una bestia de carga resignada, irreverente; el león allana el terreno creando libertad. “¿Para qué necesita el espíritu al león? ¿No es suficiente el animal robusto que se abstiene y es respetuoso? Todavía no puede crear el león valores nuevos; pero sí tiene poder para hacerse libre para la nueva creación". ${ }^{71}$

El león es una bestia, un animal de rapiña, un depredador, se roba la libertad para preparar el terreno, para pensar de otra manera. Finalmente, el niño es un inicio, a este le es lícito crear nuevos valores. A partir de esta metáfora podemos situar en el pensamiento nietzscheano un proceso a través del cual la historia global nos convierte en camellos, es decir, bestias de carga, que llevamos de forma resignada el pasado a cuestas, entendida la historia tal y como lo señalara más adelante Gadamer: "Zaratustra sabe muy bien que en todos nosotros habita también el alma del camello, dispuesta a soportar sobre su joroba la carga de los valores establecidos". ${ }^{72}$

El león, en cambio, utiliza sus garras, se autodetermina y se otorga el derecho de romper, de rasgar esa historia, para a partir de allí crear la libertad. El león es fuerte, una fuerza que está asentada, está estructurada o constituida a partir de una crítica de los valores morales. Elegir el león es genealogía, porque rasga la historia, rasga los valores morales y nos prepara para la libertad.

Ahora bien, esta labor de la genealogía es ardua, paciente y minuciosa, por cuanto debe analizar el espacio, el lugar, el contexto del terreno, entendido como lo señalaba el propio filósofo alemán: como un pantano en el que se muestran en la superficie algunos aspectos de la realidad misma, pero en cuyo fondo, en la materia gris, en el lodo, se encuentran asentados los archivos sobre los cuales reposan o han sido construidos los valores morales:

La dirección hacia la efectiva historia de la moral, y ponerla en guardia, en tiempo todavía oportuno, contra esas hipótesis inglesas que se pierden en el azul del cielo. ¡Pues resulta evidente cuál color ha de ser cien veces más importante para un genealogista de la moral que justamente el azul; a saber, el gris, quiero decir, lo fundado en documentos, lo realmente comprobable, lo efectivamente existido, en una palabra,

70 Federico Nietzsche, Asi hablaba Zaratustra. Madrid: Ediaf, 1998, p. 52.

71 lbíd., p. 53.

72 Dolores Castillo, Prólogo, en Federico Nietzsche, Así hablaba Zaratustra. Madrid: Ediaf, 1998, p. 28. 
toda la larga y difícilmente descifrable escritura jeroglífico del pasado de la moral humana? ${ }^{73}$

El genealogista deberá estar dispuesto a explorar estas profundidades del pantano a través de nuevas rutas, caminos no transitados previamente, y a partir de esa información obtendrá los elementos necesarios para generar un tipo de conocimiento hasta el momento inexistente. En consecuencia, la historia tradicional, la historia global, supone que un acontecimiento debe interpretarse en una sola dirección, es decir, en sentido de su aporte a la evolución y el progreso de la sociedad humana, lo cual, según Hegel, es un proceso acumulativo, lineal, siempre ascendente. Esa dirección forma parte del destino de la humanidad o de la realización de la razón como idea del progreso de la humanidad; mientras que la genealogía implica rupturas, acontecimientos que surgen en contextos determinados, inexistencia de relatos aglutinantes, organizadores.

En la genealogía, el acontecimiento tiene múltiples interpretaciones, está desligado de la pretendida razón universal y del antropocentrismo, es una irrupción, una invención. El acontecimiento aparece descrito tal como se produce en la realidad social, sin que la razón basada en parámetros de normalidad le deforme a la manera de una ortopedia.

Mientras que la genealogía trabaja con documentos, archivos, instrumentos precisos, con acontecimientos que quedan plasmados en archivos históricos, obras de arte, discursos de gobernantes, reglamentos de instituciones, etcétera, la historia global trabaja con conceptos, con categorías, con relatos, tales como Dios, evolución, sistema, progreso. Ello implica que la historia de los acontecimientos es una sucesión temporal y encuentra un hilo argumentativo lineal que los agrupa a todos ellos; mientras que la genealogía, desde un análisis del acontecimiento, la singularidad y la diferencia, plantea una descripción a partir de la ruptura, de las fisuras de aquella excepcionalidad.

La genealogía se aparta de las visiones de la metafísica, la ontología, las tendencias naturalistas de los acontecimientos sociales y pone de manifiesto el carácter relativo y contingente de los discursos de verdad, que desde el punto de vista de la historia global se muestran como absolutos, permanentes, ahistóricos, naturales, ontológicos o metafísicos; más bien son construcciones que datan de 
un momento histórico determinado en las que se hacen manifiestos los intereses y las oscuras luchas de poder. La genealogía reivindica la idea de invención. Mientras que la historia se preguntará por el origen, es decir, por la inscripción de cierto acontecimiento o institución dentro de la naturaleza humana, la genealogía entenderá que tal o cual acontecimiento o institución han sido inventados, son recientes, y además han podido desarrollarse en un contexto determinado. Ese contexto es el conjunto de relaciones sociales y prácticas sociales que crean normas y discursos de verdad. Estas normas permiten pensar de acuerdo con los límites allí establecidos. De esta manera, en cada época las normas y los límites de lo que puede ser pensado varían y, por lo tanto, también lo hacen los acontecimientos.

Esta posición representa una ruptura de la historia como autoridad, como pasado, y también una necesidad de construir un planteamiento que nos permita mirar hacia delante prospectivamente. Así, a partir de los planteamientos de Nietzsche, la genealogía está definida como invención, que no origen, de las instituciones a partir de prácticas sociales, es decir, entendidas ellas como lugar, como espacio a partir del cual una institución es inventada y puede desarrollarse de manera fructífera. Foucault está indicando a partir de las nociones de Nietzsche sobre la genealogía que el bien y el mal, la normalidad y la anormalidad, la desviación, etc., no tuvieron un origen, es decir, no están inscritas en lo absoluto en la naturaleza humana, sino que más bien fueron invenciones que terminaron por constituirse gracias a las prácticas sociales existentes dentro de ciertos contextos culturales:

Para Nietzsche la invención —Erfindung — es, por una parte, una ruptura y por otra algo que posee un comienzo pequeño, bajo, mezquino, inconfesable. Este es el punto crucial de la Erfindung. [...] El conocimiento fue, por lo tanto, inventado. Decir que fue inventado es decir que no tuvo origen, o lo que es lo mismo y de manera más precisa aunque parezca paradójico, que el conocimiento no está en absoluto inscrito en la naturaleza humana. El conocimiento no constituye el instinto más antiguo del hombre, o a la inversa, no hay en el comportamiento humano, en los apetitos, en el instinto humano, algo que se parezca a un germen del conocimiento. ${ }^{74}$

Existe una voluntad oscura detrás del conocimiento. En el centro de la producción de la verdad se encuentran las relaciones de poder. Esto es a lo que 
Nietzsche denominaba una política de la verdad, es decir, para comprender el surgimiento de la verdad no debemos acercarnos a ella como filósofos, sino más bien como políticos. El pensamiento crítico ilustrado tiene según Foucault una propuesta a la que él denomina la ontología del presente, según la cual la historia tradicional se hace contando periodos largos, grandes continuidades, fenómenos inalterados por siglos, y deja de lado lo realmente ocurrido en las luchas, sobre todo aquellos acontecimientos que no han tenido la suerte de ser contados.

Emerge otro tipo de historia, una que no agrupa fenómenos alrededor de un centro único, un solo principio, una visión de mundo, sino más bien una arqueología que muestra diferentes series, cronologías, donde no es posible localizar un centro privilegiado. La arqueología cuestiona las continuidades, las teleologías, se opone a una historia organizada. De allí es lógico señalar la imposibilidad de englobar la historia, de hacerla continua y progresiva; ello es posible solo a través de la idea de un sujeto racional, de una razón que progresa, de un metarrelato que organiza todos los acontecimientos.

Es posible entonces señalar que genealogía y arqueología son método y estrategia en Foucault. La genealogía nietzscheana es la estrategia que utiliza para romper con el tradicional enfoque de la historia y de la metafísica. Muchos de los objetos de conocimiento a los que creíamos como realidades dadas, apriorísticas, inmutables, inscritas en la naturaleza humana, en realidad son construcciones sociales, son invenciones. Así ocurre con el delito, el delincuente, el sistema penal, el libre albedrío, la criminalidad, las causas de la criminalidad, la anormalidad del criminal, la inimputabilidad, la pena, la privación de la libertad, la prevención de la pena, las prisiones, los prisioneros, la criminología, la política criminal, el derecho penal. Todas ellas son invenciones recientes.

Todos estos acontecimientos forman parte de la modernidad, del capitalismo, de las sociedades disciplinarias, y son absolutamente ajenos a la época antigua, al Medioevo, a la inquisición, al feudalismo, al esclavismo, al mundo precolombino, etc. El sistema penal es un invento de la modernidad. La arqueología será el método a través del cual podrá rastrearse el surgimiento del acontecimiento, es decir, la invención. No puede ser la historia, dado que esta ha organizado los acontecimientos en regularidades, ha omitido las minucias, ha deformado los acontecimientos al inscribir en ellos el mito. La arqueología, en cambio, rastrea el archivo, el dossier, la obra de arte, el discurso, los huesos del dinosaurio. 
El arqueólogo encuentra el acontecimiento en su estado natural, sin distorsiones, va a la fuente directa: a los archivos.

¿Pero qué es lo que investiga Foucault?, ¿cómo pueden entenderse esos acontecimientos a los que ha llegado gracias a la genealogía y la arqueología? La filosofía de Foucault puede entenderse como un análisis de dispositivos, como en concreto lo expresa Deleuze. ${ }^{75}$ Pero un dispositivo no es un objeto de conocimiento, no es una cosa o fenómeno, no es propiamente un problema. ¿Qué es, entonces, un dispositivo?

A nosotros, los mestizos de América Latina, ya no nos quedan imágenes del recuerdo, somos los intestados de la memoria, solo nos quedan las palabras. "Palabras, palabras desplazadas y mutiladas, palabras de otros". ${ }^{76}$ Lo Real es una porción del mundo que distinguimos del infinito complejo de acontecimientos a través del entendimiento, el cual, como una navaja bien afilada, hace un corte que da origen al dispositivo. El dispositivo es pues el mundo que emerge de este corte. Al igual que una madeja de hilo, el dispositivo es un conjunto de hilos de múltiples colores, abigarrados y complejos, dentro de los que se distinguen hilos luminosos, constituidos por los discursos de verdad que a veces se comportan como normas y otras como saberes. ${ }^{77}$

Estos hilos temporales muestran el acontecimiento, es decir, la historia siempre cambiante, con una lógica de la diferencia que desestructura cualquier intento por mostrar líneas de continuidad entre un dispositivo y otro. También hilos que describen el espacio, aquellos lugares en los que surgen los acontecimientos y se reproducen fructíferamente. La preguntas de Nietzsche sobre estos espacios son: ¿cómo han podido surgir, cómo han sido inventados estos acontecimientos?, ¿gracias a qué terreno fértil han podido germinar y crecer teles artificios? ${ }^{78}$

Esos espacios son cerrados o abiertos. Los espacios cerrados son típicos de la modernidad, de las sociedades de la disciplina para Foucault, o de las sociedades del control para Deleuze. ${ }^{79}$ Los abiertos están afuera del dispositivo, o adentro,

75 Gilles Deleuze, ¿Qué es un dispositivo?, en Autores Varios, Michel Foucault: filosofo. Barcelona: Gedisa, 1999. 76 Jorge Luis Borges, El inmortal, en El Aleph. Madrid: Alianza, 2006, pp. 7-28.

77 Gilles Deleuze, ¿Qué es un dispositivo?, op. cit.

78 Federico Nietzsche, La genealogía de la moral, op. cit.

79 Gilles Deleuze, Conversaciones 1972-1990: Poscriptum sobre las sociedades de control. Barcelona: Pre-Textos. 
muy en el fondo de la madeja de hilo, ocultos e innombrados. Estos son otros espacios. Finalmente, en la superficie, por todos lados, trenzando, apretando la madeja, están los hilos con los que se hace el nudo, es decir, las relaciones de poder. En suma, podríamos afirmar que lo real está constituido por los discursos, las prácticas y las relaciones de poder, y todo ello ocurre dentro espacios o epistemes que producen la verdad (figura 1).

Figura 1. Componentes y relaciones del dispositivo

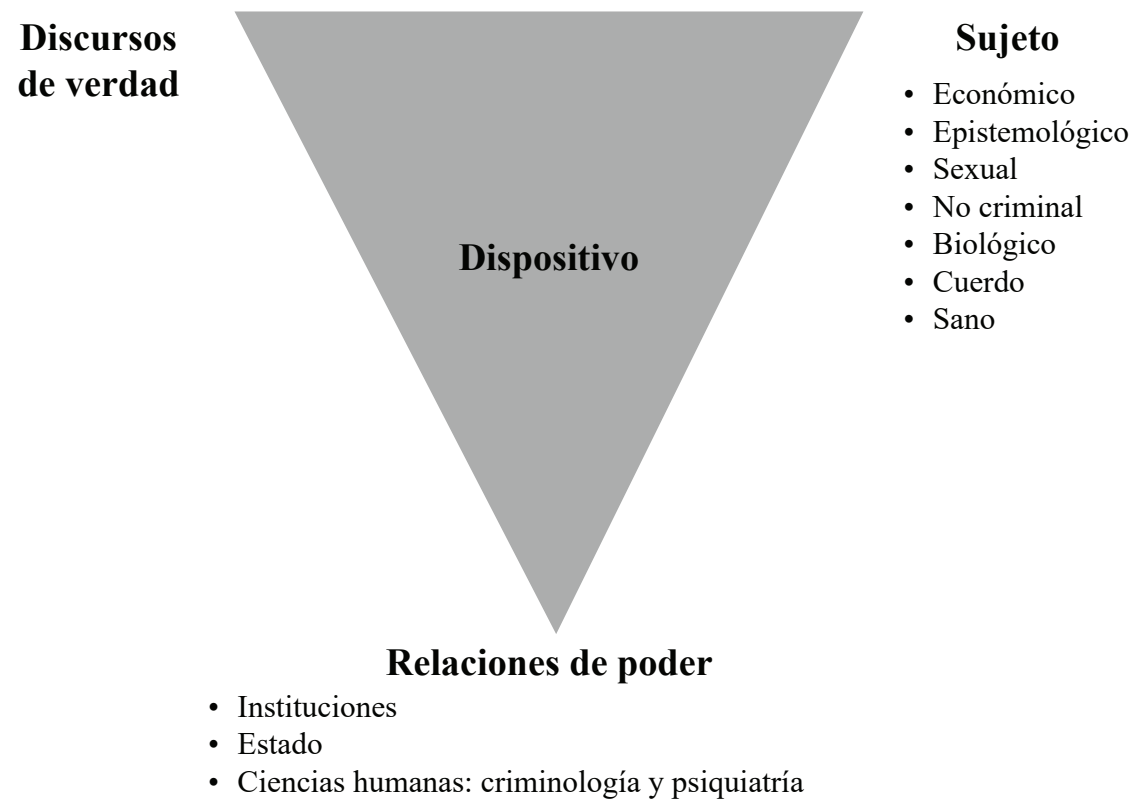

Fuente: autores.

A partir de la anterior figura podemos sintetizar la idea de dispositivo. El dispositivo es un pedazo de realidad. Dado que la realidad es inconmensurable, el hombre utiliza métodos para observarla. Estos métodos sirven para alumbrar porciones de la realidad. El dispositivo es esa porción de la realidad que incluye la mirada del hombre. El haz de luz que ilumina y lo iluminado forman parte del dispositivo. El dispositivo, en cuanto porción de la realidad, está lleno de acontecimientos. Allí aparecen las prácticas sociales, los discursos de verdad que surgen de ellas, las normas (que no son más que discursos de verdad elevados), 
los saberes y las ciencias, los sujetos, las relaciones de poder, las resistencias, los archivos, etc. De todo ello, Foucault distingue tres acontecimientos o, en otras palabras, tres líneas de luz que aparecen dentro de todo dispositivo para Foucault: la verdad, el poder y el sujeto.

\section{La sociología comprensiva de Max Weber}

La criminología crítica o sociología jurídico-penal ${ }^{80}$ es un saber que pretende abordar una serie de problemáticas referidas al sistema penal desde un punto de vista opuesto al de la criminología positivista. Por esta razón, es muy difícil que se tenga una idea más o menos clara de su objeto de estudio, su punto de vista o su método, sin haber antes entendido estos aspectos en el interior de la criminología positivista.

Si se tiene en cuenta el origen de la criminología positivista y, posteriormente, la pretendida superación de la visión determinista de esta, se entenderá el locus de enunciación de la criminología crítica y su forma de proceder. En este sentido, la criminología crítica desplaza la mirada del fenómeno criminal que parte del sujeto criminal hacia los procesos de criminalización, los cuales conforman y estructuran el actuar del sistema penal. Para este saber crítico, el delito deja de ser un fenómeno negativo para la sociedad que puede explicarse a través de la relación causal entre delincuente (sus características físicas y psíquicas) y el crimen, y pasa a convertirse en una construcción social compleja y dinámica en la que participan una serie de procesos de criminalización que forman parte del sistema penal y, de modo más general, de todo el sistema de reacción y control social de los comportamientos desviados. De ahí que la criminología crítica resulte indisolublemente relacionada con la sociología.

El análisis de la criminalidad está enmarcado en una serie de relaciones complejas. La importancia para la sociología del análisis que se propone radica principalmente en la forma de abordar la problemática penal. Esta forma de abordar al castigo penal parte de una mirada interdisciplinaria. Dicha mirada es posible si se considera al derecho penal como una construcción social. Desde esta perspectiva, el derecho penal, lejos de ser considerado como un conjunto de normas, es más bien un conjunto de procedimientos y mecanismos de control social que 
presentan como punto cúspide la imposición de un dolor a través del castigo penitenciario. No obstante, para poder llegar a este abordaje es necesario hacer un análisis detallado del castigo penal y, sobre todo, proponer un cambio de objeto; es decir, mientras que para los estudios ortodoxos de la criminalidad el derecho es un conjunto de normas, para el pensamiento crítico, el derecho penal es un conjunto de relaciones de fuerza que se ejercen a través de ciertos mecanismos y procedimientos que merecen ser analizados.

De esta manera, el sistema penal — para nosotros, la cuestión criminal— se convierte en un problema de investigación complejo en el que hay distintos niveles de análisis. Los análisis superficiales se dirigirán al ámbito normativo, a los códigos penales o a las teorías que justifican políticamente la existencia de la prisión en nuestras sociedades (justificación de lo injustificable). Una observación más profunda, una excavación en los mecanismos de vigilancia, control y exclusión de la cárcel —en pocas palabras, a los mecanismos en concreto de castigar (materialidad del castigo)—, nos mostrará la dominación que se ejerce a través del castigo penal. Esta dominación se encuentra oculta por los saberes de la dogmática penal, por las políticas criminales o, en general, por todo un complejo científico-filosófico que se inaugura con la Ilustración y su posición utilitarista del castigo penal.

Es necesario que en este momento de la investigación se distingan los rasgos fundamentalmente sociológicos de la investigación de acuerdo con los lineamientos expresados por Max Weber. ${ }^{81}$ En estos trabajos, Weber aclara algunos conceptos centrales de la sociología, de manera tal que quede claro aquello que toda sociología empírica entiende de hecho cuando habla de las mismas cosas. ${ }^{82}$

Ahora bien, es necesario distinguir en esta parte de la investigación las afirmaciones propiamente sociológicas de las valoraciones que hemos hecho en términos de ideología o de racismo. En palabras de Max Weber, es posible que en la investigación sociológica - especialmente en la producción de conocimiento científico en el interior de la sociología política - se expresen juicios de valor, siempre y cuando se distinga entre saber empírico propiamente sociológico y juicios de valor que se desprenden de dichos estudios sociológicos. Para aclarar

81 Max Weber, Economía y sociedad (tomo 1, primera parte: Conceptos fundamentales). México: Fondo de Cultura Económica, 1979.

82 Max Weber, Ensayos sobre metodología sociológica. Buenos Aires: Amorrortu, 1978. 
esta situación nos apoyaremos fundamentalmente en lo que Weber ha expresado en el texto La objetividad del conocimiento en la ciencia social y en la política social. ${ }^{83}$

En este texto, Weber rechaza la opinión de que la sociología política produce y debe producir juicios de valor a partir de una ideología específicamente económica. Por tratarse de una ciencia empírica, debe rechazarse la idea de que la sociología tiene como tarea el establecimiento de normas ideales, con el fin de derivar de ellas recetas para la praxis.

El problema radica básicamente en considerar que los juicios de valor están basados en determinados ideales, es decir, son de carácter subjetivo. Weber se opone a esta consideración y más bien se pregunta lo siguiente: ¿qué significa y qué se propone la crítica científica de ideales y juicios de valor? En este sentido, el problema básico es el estudio científico de los juicios de valor, es decir, la manera en que es posible enjuiciar en la ciencia social de forma crítica y de manera objetiva.

Aun cuando en el análisis de los problemas políticos y sociales intervienen los juicios de valor como ideas regulativas y, por lo tanto, el punto de vista del científico, es necesario que se distinga entre el deber científico de ver la verdad de los hechos del deber práctico de defender nuestros propios ideales. En otras palabras, tratar de partir de ciertos ideales sin que con ello se ponga en entredicho el valor científico del análisis teórico.

Para llevar a cabo esta doble tarea es necesario que el científico manifieste juicios de valor, y a través de ellos, los ideales que lo animan deberán cumplir con ciertas obligaciones:

[Se trata de] recordar en todo instante a los lectores y a sí mismos cuáles son las escalas de valor con las cuales se mide la realidad y de donde se deducen los juicios de valor, en lugar de entremezclar de forma imprecisa los diversos valores. ${ }^{84}$

La exposición de ideales y las discusiones al respecto no son científicas, y en ese sentido, aunque se haga un análisis sobre estas, no deben confundírselas con la ciencia social. Existe, por ende, un tipo de conocimiento objetivo en el campo

83 Max Weber, La objetividad del conocimiento en la ciencia social y en la política social. Madrid: Alianza, 2009.

84 Ramón Rensendiz García, El pensamiento sociológico clásico. México: Universidad Nacional Autónoma de México, 1998, p. 318. 
de las ciencias sociales. Luego, es necesario hacer una distinción entre juicio de valor y saber empírico. Ahora bien, es necesario aclarar el concepto de Weber sobre la sociología y el significado de la acción social. Por sociología entiende "una ciencia que pretende entender, interpretándola, la acción social para de esa manera explicarla causalmente en su desarrollo y efectos". ${ }^{85}$

Por acción entiende "una conducta humana (bien consista en un hacer externo o interno, ya en un omitir o permitir) siempre que el sujeto o los sujetos de la acción enlacen a ella un sentido subjetivo" ${ }^{86}$ Y por acción social expresa que es "una acción en donde el sentido mentado por su sujeto o sujetos está referido a la conducta de otros, orientándose por esta en su desarrollo". ${ }^{87}$

Ahora bien, en estos estudios sobre los conceptos centrales y los fundamentos metodológicos de la sociología, Weber nos aclara en once parágrafos los fundamentos metodológicos que subyacen a las anteriores definiciones. En el primer parágrafo nos define el concepto de sentido y la manera en que este se entiende en el terreno de la sociología, a diferencia de otros campos de conocimiento como la ética o la lógica, donde se trata de una investigación del sentido objetivamente justo o verdadero y en una dirección metafísica. Por sentido entiende "el sentido mentado y subjetivo de los sujetos de la acción, bien sea a) existente de hecho [...] b) como construido en un tipo ideal con actores de ese carácter". ${ }^{88}$

En el parágrafo segundo hay que distinguir entre una acción con sentido y una acción como conducta simplemente reactiva. La acción con sentido es comprensible. Algunas acciones con sentido, como los procesos místicos, no pueden ser comprendidas a plenitud, por lo que no pueden ser comunicables por medio de la palabra. Para comprender la acción no es necesaria que esta sea producida por uno mismo; es posible comprender los procesos ajenos. ${ }^{89}$

Ahora bien, en términos de Weber, la sociología compresiva es la que debe encargarse del estudio de la acción social. Definamos a continuación los principales elementos de dicha ciencia.

85 Max Weber, Economía y sociedad, tomo 1..., op. cit., p. 5.

86 Ibíd., p. 5.

87 Ibíd., p. 5.

88 Ibíd., p. 6.

89 Max Weber, Economía y sociedad, tomo 1..., op. cit., p. 6. 


\section{Sentido de una sociología comprensiva}

Max Weber nos aclara inicialmente que la conducta humana (externa o interna) muestra ciertas regularidades, las cuales son interpretadas por la vía de la comprensión. Ahora bien, de todos los comportamientos humanos, aquellos que poseen un grado mayor de evidencia son los racionales con arreglo a fines, es decir, aquellos comportamientos que se orientan "exclusivamente hacia medios representados (subjetivamente) como adecuados para fines aprehendidos de manera (subjetivamente) unívoca". ${ }^{90}$

No obstante, el comportamiento racional con arreglo a fines configura el tipo ideal más apropiado para el análisis sociológico. Esto no quiere decir que otro tipo de comportamientos como el éxtasis, la experiencia mística e incluso los estados emocionales y afectos irracionales con relación a fines no puedan ser comprendidos. En este sentido, el objeto de la sociología comprensiva no lo constituye cualquier comportamiento, sino la acción.

Por acción Weber entiende un comportamiento especificado por un sentido (subjetivo). De todas las acciones con sentido, aquellas que revisten una importancia relevante para la sociología son, primero, "la conducta que está referida, de acuerdo con el sentido subjetivamente mentado del actor, a la conducta de otros" "11; segundo, aquella que está "codeterminada en su decurso por esta su referencia plena de sentido"; y, tercero, aquella que "es explicable por vía de la comprensión a partir de este sentido mentado (subjetivamente)". ${ }^{92}$

\section{Relación con la psicología}

La acción comprensible es aquella que se realiza con arreglo a fines (subjetivos), siguiendo medios a los que se les considera apropiados (subjetivamente) para el logro de lo que se proponga. Ello no implica que se pretenda deducir dicha subjetividad a partir de estados de cosas psíquicas. En la sociología comprensiva se deduce la acción de acuerdo con lo regular, es decir, según las reglas de la experiencia. En este sentido, mientras la acción comprendida esté más orientada a un tipo de racionalidad 
regular, menos tendrá que ser comprendida teniendo en cuenta consideraciones psicológicas. Por lo tanto, la sociología comprensiva no forma parte de la psicología.

\section{Relación con la teoría jurídica}

La sociología comprensiva trata al individuo aisladamente, teniendo en cuenta su obrar como unidad última. No entiende al individuo como un complejo de procesos psíquicos, químicos, etc.; el núcleo básico de lo comprensible para la sociología comprensiva será el comportamiento del individuo susceptible de interpretación con sentido. El derecho trata al Estado e incluso al individuo como personas de derecho, es decir, haciendo abstracción y basando dicha definición en el sentido normativo que esta implica. En la sociología, por el contrario, se trata de modos determinados del actuar humano en sociedad. Así, los preceptos jurídicos serán considerados como representaciones de los hombres que orientan racionalmente su actuar hacia ciertas expectativas. En otras palabras, dichos preceptos jurídicos (Estado, persona de derechos, etc.) dirigen racionalmente el actuar de los hombres hacia ciertas expectativas.

\section{El actuar en comunidad}

Sobre este aspecto Weber distingue:

1) Un comportamiento históricamente observado, o bien 2) un comportamiento construido teóricamente, como objetivamente posible o probable, realizado por individuos en relación con comportamientos reales, o representados como potenciales, de otros individuos. ${ }^{93}$

En el actuar en comunidad, la acción está subjetivamente provista de sentido a la conducta de otros hombres. El actuar racional del individuo con relación a fines en comunidad es un actuar de un individuo orientado racionalmente hacia unas expectativas de una determinada conducta por parte de los otros. Estas expectativas o chances que orientan la acción en comunidad de un individuo pueden "fundarse subjetivamente en el hecho de que el actor se entiende con los otros, ha entrado en acuerdos con ellos". ${ }^{94}$ El actuar en comunidad del individuo puede también estar orientado por valores o deberes, y no solo por expectativas.

93 lbíd., p. 190.

94 lbíd., p. 190. 


\section{La asociación y el actuar en sociedad}

El actuar en sociedad es un tipo de actuar en comunidad orientado hacia expectativas alentadas por ordenamientos, los cuales pueden ser un requerimiento unilateral o bilateral de unos hombres a otros, es decir, como un acuerdo entre los hombres. También puede darse el caso de una infracción al ordenamiento, en la cual es consciente dicha infracción.

También puede darse el caso de un actuar real de los individuos de acuerdo con múltiples ordenamientos que se contradigan entre sí. Ahora bien, el tipo ideal racional de la asociación es, para Weber, la unión de fines, "es decir, el actuar en sociedad con un ordenamiento del contenido y de los medios de acción social convenido por todos los participantes de manera racional con relación a fines". ${ }^{95}$

\section{El consenso}

Hay formas de actuar en comunidad que no están orientadas hacia un ordenamiento pactado, pero que transcurren como si se hubiese acordado uno:

Por consenso entendemos el hecho de que un actuar orientado según expectativas del comportamiento de otras personas tenga, a causa de ello, una chance empíricamente válida de ver cumplidas esas expectativas, precisamente porque subsisten objetivamente la probabilidad de que estos otros trates estas expectativas a pesar de la inexistencia de un pacto, como válidas y provistas de sentido para su conducta. ${ }^{96}$

No obstante, consenso no puede ser identificado con pacto tácito. Un consenso vigente como tipo puro no contiene estatuto ni pacto alguno. Los individuos que entran a una comunidad pueden desconocerse entre sí; sin embargo, puede existir un consenso como una norma inviolable. En este sentido es necesario distinguir entre un actuar de los individuos condicionado por las masas $-\mathrm{o}$ de una actuar de estos orientado por un acuerdo - y un actuar de los individuos orientados por consenso. 